\title{
Assessing Struvite Formation Potential at Wastewater Treatment Plants
}

\author{
Kazi P. Fattah
}

\begin{abstract}
Wastewater treatment plants, especially those employing secondary treatment and anaerobic sludge digestion, have historically encountered phosphate precipitates, one of the commonest being struvite, that foul and encrust the sludge return lines, and the associated pumps and valves. This growth of 'uncontrolled' struvite increases pumping and maintenance cost, as well as reduces the overall capacity of the plant piping system in terms of lost hydraulic capacity and lowered biological treatment capacity. Although uncontrolled formation of struvite can be a nuisance, however, controlled production of struvite can prove beneficial to treatment plants. This is accomplished through reducing maintenance costs, as well as providing extra revenue from the sale of the struvite crystals as fertilizers. This paper investigates what can and should be done before struvite-related problems hamper efficient operation of the treatment plant. A case study carried out at a wastewater treatment plant showed the influence of nutrient loading in cases where nutrient treatment is not carried out. The three locations investigated all has a supersaturation value greater than unity; this indicated that struvite formation potential was high. The amount of phosphorus and nitrogen looping within the treatment plant was as high as $21 \%$ and $20 \%$, respectively.
\end{abstract}

Index Terms-Wastewater, struvite, sustainable development, supersaturation ratio.

\section{INTRODUCTION}

Struvite, magnesium ammonium phosphate hexahydrate (MAP), is a crystalline structure that occurs naturally in rotting organic material such as guano deposits and cow manure. It has also been observed in sludge derived from the anaerobic digestion of animal farming liquid wastes and agricultural wastes. As well as being found in biologically treated wastewater sludge, struvite has been recognized as a common constituent of renal calcui of both humans and animals [1].

Accumulation of struvite (MgNH4PO4.6H2O) on pipe walls and equipment surfaces of anaerobic digestion and post digestion processes is a problem that plagues the wastewater treatment industry [2]. Struvite is well known for plugging pipes and fouling pumps, aerators, screens and other equipment. Remediation is often impractical and, when possible, is costly in terms of labor, materials and system downtime. The pellets anchor to sludge particles in suspension and to surfaces of equipment, tank and pipe walls in contact with digestion sludge. Pellet growth can be rapid and, if left unchecked, struvite accumulation can foul mechanical equipment and clog pipes within months [3], [4].

Manuscript received September 7, 2012; revised September 30, 2012

Kazi P. Fattah is with the American University of Sharjah, Sharjah, United Arab Emirates (e-mail: kfattah@aus.edu).
Fig. 1 illustrates occasions where struvite was formed in the piping at treatment plants.

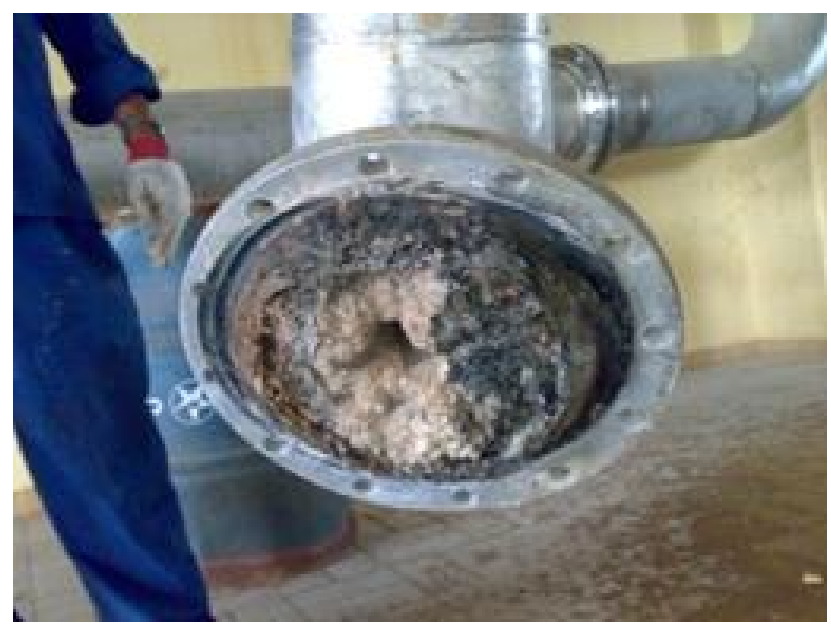

Fig. 1. Clogging of a post digestion pipe by struvite at a treatment plant (location confidential)

\section{A. Factors Affecting Struvite Formation}

Several factors influence the formation of struvite. The important parameters are (1) concentrations of the constituent ions (ortho-phosphate (P), ammonium (NH4-N) and magnesium), (2) the $\mathrm{pH}$, and (3) temperature of the wastewater. The concentration of the constituent ions depends on the characteristics of the influent and the amount of treatment the source water received. At secondary treatment plants, magnesium is usually the limiting ion in the formation of struvite in the system. However, since the concentration is usually very low, no appreciable increase in return magnesium (in the centrate) is expected over the life of the treatment plant. On the other hand, the ammonium concentration is usually much higher than both magnesium and phosphate, but its percentage increase in the return line is low. The ortho-phosphate concentration in the return line is of great importance. When waste activated sludge is digested anaerobically, much of the phosphate, which was removed in the main treatment train are re-released under the anaerobic conditions. Various studies show that $26 \%$ to $90 \%$ of the phosphorus entering the head of the treatment plant is due to phosphorus feedback, that is, phosphorus in the return liquors [5]. Some plants have even reported additional phosphorus loads of up to $100 \%$ [6].

Consequently, the phosphorus circulates in a loop within the treatment system, thus increasing the overall P load. The $\mathrm{pH}$ can be increased locally by sudden pressure drops, which can result in the stripping of carbon dioxide, and thereby increasing the $\mathrm{pH}$. Temperature appears to influence the formation potential to a great deal [7]. 


\section{Finding OUt IF THERE IS A STRUVITE Problem}

It is imperative that treatment plant determines if it has a struvite-related problem or not before the struvite accumulates to a degree that hampers efficient treatment process. Therefore, it is necessary to determine, or calculate, the conditions that will assist struvite formation and growth.

The general equation for the formation of struvite is given by (1).

$$
\mathrm{Mg}^{2+}+\mathrm{NH}_{4}^{+}+\mathrm{HPO}_{4}{ }^{2-}+6 \mathrm{H}_{2} \mathrm{O} \leftrightarrow \mathrm{MgNH}_{4} \mathrm{PO}_{4} \cdot 6 \mathrm{H}_{2} \mathrm{O}+\mathrm{H}^{+}
$$

\section{A. Supersaturation Ratio (SSR)}

This value determines the possibility for the formation of struvite at any location. Any value greater than unity indicates that formation is "possible". However, an SSR of just unity does not necessarily mean that struvite will form rapidly or to a great extent. In order to have rapid struvite growth and accumulation, a SSR above unity is usually required. At pilot-scale studies involving deliberate and controlled struvite formations, a SSR value of 3-5 is used for optimal struvite growth in a struvite crystallizer [8]. The supersaturation ratio is given by (2).

$$
\begin{aligned}
& \mathrm{SSR}=\mathrm{P}_{\mathrm{s}} \text {-sample/ Ps-equilibrium } \\
& P_{s}-\text { sample }=\left\{M g^{2+}\right\}\left\{N H_{4}^{+}\right\}\left\{\mathrm{PO}_{4}^{3-}\right\}
\end{aligned}
$$

$\mathrm{P}_{\mathrm{s}}$-sample: the solubility product of the sample.

Ps-equilibrium: the solubility product in equilibrium under the same conditions ( $\mathrm{pH}$, conductivity and temperature) as that of the sample.

In order to determine the solubility product, the total soluble ortho-phosphate, ammonium and magnesium have to be determined. The total ion is a combination of species other than $\mathrm{PO}_{4}{ }^{3-}, \mathrm{NH}_{4}^{+}$and $\mathrm{Mg}^{2+}$, as shown in (3-5). The [ ] brackets indicate ion concentration in moles per liter, without correction for activity. However, in the calculation for the supersaturation ratio, these concentrations are corrected for activity. The Ps-equilibrium value was obtained from a series of laboratory experiments [9] conducted by the research group.

$$
\begin{gathered}
\mathrm{T}-\mathrm{PO}_{4}=\left[\mathrm{H}_{3} \mathrm{PO}_{4}\right]+\left[\mathrm{H}_{2} \mathrm{PO}_{4}^{-}\right]+\left[\mathrm{HPO}_{4}{ }^{2-}\right]+\left[\mathrm{PO}_{4}{ }^{3-}\right] \\
\mathrm{T}-\mathrm{NH}_{4}-\mathrm{N}=\left[\mathrm{NH}_{3}\right]+\left[\mathrm{NH}_{4}{ }^{+}\right] \\
\mathrm{T}-\mathrm{Mg}=\left[\mathrm{Mg}^{2+}\right]+\left[\mathrm{MgOH}^{+}\right]
\end{gathered}
$$

The \{\} brackets in (2) indicate ionic concentration in moles per liter, corrected for activity. This involves the speciation of analytically determined concentrations using published acid and base dissociation constants, as well as an adjustment for activity. The activity is a function of the concentration of the ion and its activity coefficient, $\gamma$. The activity is given by the Güntelberg approximation of the Debye-Hückel equation shown in (6) [10].

$$
\log \gamma=\frac{0.5 z^{2} \sqrt{\mu}}{1+\sqrt{\mu}}
$$

where,

$\gamma=$ the activity coefficient for the species of interest

$\mathrm{z}=$ the ionic charge of the species of interest

$\mu=$ ionic strength

The ionic strength of the solution can be determined based on conductivity measurements using the conversion factor described in (7).

$$
\mu=1.6 \times 10^{-5} \mathrm{EC}
$$

\section{B. Struvite Formation Potential (SFP)}

The struvite formation potential is a term that is used as the primary indicator in the risk assessment analysis. This is a relative value that depends on the SSR value at a particular system. The probability of the increase in the concentrations of struvite constituent ions (ammonium, magnesium and phosphate) and conditions ( $\mathrm{pH}$, temperature and conductivity) at the location will determine the extent of the formation potential. In order to determine these factors of struvite formation, it is necessary for treatment plants to carry out studies to determine this struvite formation potential at different "hot spots" - such as, pumps and elbows after anaerobic digestion - within the treatment system where struvite is "likely" to occur and accumulate.

\section{NUTRIENT LOOPING}

One of the problems of no nutrient (nitrogen and phosphorus) removal in secondary treatment plants is the looping of nutrients in the treatment system. Lopping is essentially the return of nutrient-rich supernatant (or centrate) back to the headworks of the treatment plant. Although recent treatment processes are increasingly removing nitrogen, there has been very little implementation of phosphorus removal worldwide. If no nutrient is removed, the concentration keeps on increasing in the treatment loop. In addition, for biological treatment processes, which has an effective criteria of BOD:N:P ratio of 100:5:1, the increase in $\mathrm{N}$ and/or $\mathrm{P}$ will decrease treatability efficiency. Therefore, it is vital that the amount of nutrient recycled is determined on a regular basis.

\section{CASE STUdY}

In 2009 a study was carried out at a wastewater treatment facility in Canada (confidential client) to determine the struvite formation potential in the post digestion system. The secondary wastewater treatment plant employs an anaerobic digester followed by centrifuge to dewater the sludge. There is no nutrient removal at the plant. At the treatment plant, the centrate is first stored temporarily in a centrate sump before it is flushed back to the headworks. The outcome of this study was to set up a bench mark for further studies to investigate the potential for controlled production of struvite from centrate which will significantly reduce the uncontrolled struvite formation in the pipe network.

Samples were taken from three locations - just after the anaerobic digester (digested sludge storage tank), just after the centrifuge (centrate) and from the centrate sump. The samples were tested for the parameters that determine SSR the concentrations of ammonia-nitrogen, phosphate, and 
magnesium, the $\mathrm{pH}$, temperature and conductivity. The samples were centrifuged for 10 minutes at 4000 RPM due to high solids content. The resulting supernatant was filtered using 0.45 micron filter paper prior to analytical measurements. All the chemical and physical parameters were tested according to Standard Methods [11].

\section{A. Supersaturation Ratio}

As mentioned previously, the SSR provides an indication of the possibility of struvite formation. Table 1 provides the calculated SSR at the three sampling points. As can be seen, all locations had a SSR value above unity, which theoretically showed that there was a potential for struvite formation. These theoretical values were validated in practical terms as well, because on inspection of the pipes, valves and pumps, struvite was found to accumulate at these locations. Thus, calculating the SSR on a regular basis can practically forecast possible struvite formation and accumulation.

TABLE I: SUPERSATURATION RATIO AT SAMPLING POINTS

\begin{tabular}{lc}
\hline Sample location & Supersaturation Ratio \\
\hline Digested Sludge Storage Tank & 2.2 \\
Centrate (after centrifuge) & 1.9 \\
Centrate Sump & 2.0 \\
\hline
\end{tabular}

\section{B. Nutrient Looping}

Table II shows the nutrient concentrations and mass loading of phosphorus and nitrogen in the treatment plant. The return represented as much as $21 \%$ of the total plant's phosphate load (from influent and centrate return), whereas, the TKN concentration of the centrate that is returned to the headworks is $1241 \mathrm{mg} / \mathrm{L}$; this represents approximately one-fifth of the new TKN mass load arriving through the influent. In terms of struvite formation potential, recirculation of phosphorus and nitrogen in the treatment process continuously increases the formation potential.

\begin{tabular}{lcc}
\multicolumn{3}{c}{ TABLE II: NUTRIENT LOOPING IN THE TREATMENT PLANT } \\
\hline Flow (MLD) & Influent & Centrate return \\
Phosphate conc. (mg/L) & 450 & 1.86 \\
Total load (kg P/day) & 2.2 & 138 \\
TKN (mg/L) & 990 & 257 \\
Total TKN load (kg/day) & 24 & 1241 \\
\hline
\end{tabular}

\section{Potential Struvite Formation between Centrifuge and Centrate Sump}

Between the centrifuge and centrate sump, a substantial decrease in phosphate and ammonia-nitrogen concentration were found. The loss of phosphate was $57.2 \mathrm{mg} / \mathrm{L}(105$ $\mathrm{kg}$ /day) while that of ammonia-N was $424 \mathrm{mg} / \mathrm{L}$ (780kg/day); this represented a change of $29 \%$ and $28 \%$, respectively. However, the simultaneous loss in $\mathrm{Mg}$ was much less pronounced, which suggests that forms other than struvite, such as metal phosphates, may have attributed to the phosphate loss. One such metal phosphate could be vivianite (iron phosphate). However, given the high SSR in both the centrate and the centrate sump, any solids formed will likely contain substantial amount of struvite.

\section{What-If Situations}

This section deals with "what-if conditions" - in other words, what if the parameters had a different value. This is more of a predictive model/scenario that can be used to justify the struvite formation potentials. It also allows the operators to determine what conditions may lead to struvite being formed, and what minimum conditions are needed to reduce formation potential. The parameter values for the figures have been assumed to be representative scenarios for that of centrate.

1) Influence of magnesium and phosphate on SSR

Fig. 2 illustrates the different scenarios related to simultaneous changes in ortho-P and magnesium. The first diagram is calculated at $\mathrm{pH} 7.7$, while the second is at $\mathrm{pH} 8.2$. The ammonium, conductivity, temperature was kept constant for both the figures (Ammonia-N $1200 \mathrm{mg} / \mathrm{L}$; temp 40C; conductivity $10,800 \mathrm{mS} / \mathrm{cm})$. What is striking between the two figures is the strong influence of $\mathrm{pH}$ on SSR. Given that the SSR was always above unity at the treatment plant, it implies that changes are needed to one, or multiple, parameters to reduce the struvite formation potential. As can be seen from the second diagram, it is imperative that the $\mathrm{pH}$ be kept as low as possible to prevent struvite buildup.
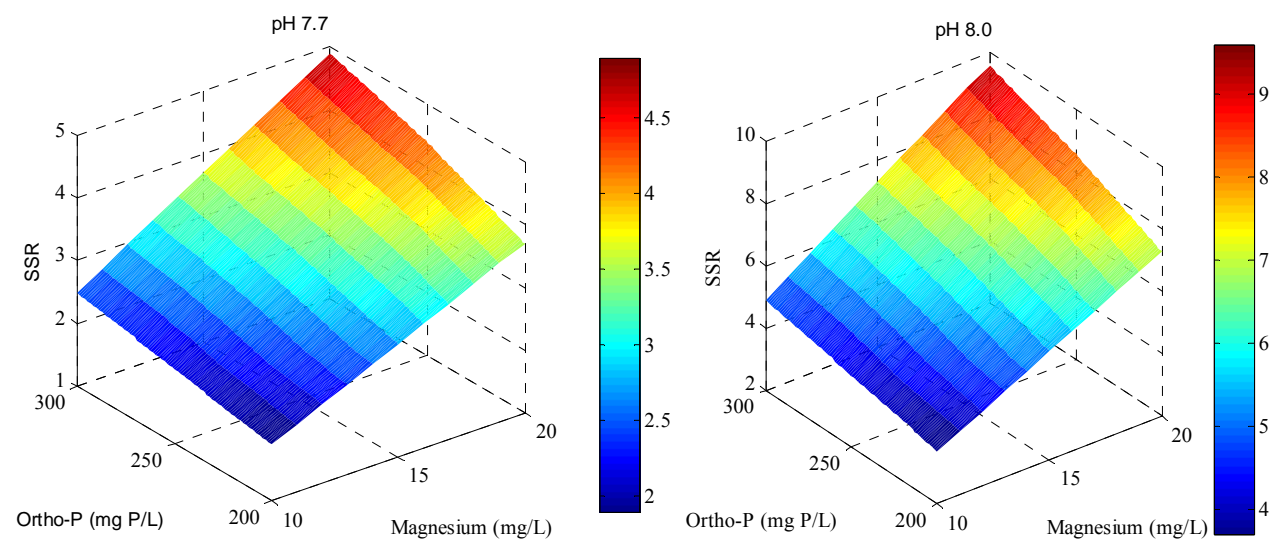

Fig. 2. Influence of ortho-P and magnesium on SSR at different $\mathrm{pH}$ values. 


\section{2) Influence of temperature and phosphate on SSR}

Fig. 3 illustrates the influence of temperature and ortho-P on SSR. The influence of temperature is especially important in places like the centrate sump, which may be subject to varying temperature during the year. As can be seen, a 5 degree change may double the SSR - this increases the struvite formation potential drastically. Thus, although in the summer month, when the temperature is high, struvite may not form, but in the cooler winters, heavy struvite may precipitate.

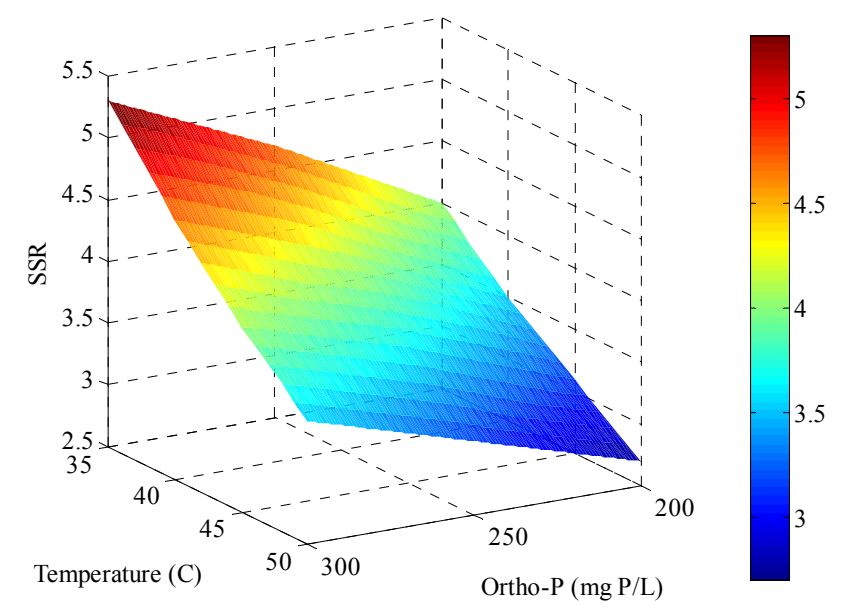

Fig. 3. Influence of temperature and ortho-P on SSR.

\section{Are There Any Solutions to the Struvite PROBLEM?}

The development of technologies for phosphorus removal offers the opportunity for recycling and phosphorus sustainability. However, there are a number of technologies both established and under development, which can be used to remove phosphorus from wastewater and can potentially be used within a sustainability strategy. Removal was initially achieved by chemical precipitation, which remains the leading technology today. More recently, however, biological phosphorus removal has become firmly established, crystallization technology has also accomplished great progress towards commercialization and technologies extending chemical precipitation to assist nutrient removal are beyond the pilot scale. In all processes, phosphorus ions in wastewater are removed by converting the phosphorus into a solid fraction. This fraction can be an insoluble salt precipitate, a microbial mass in an activated sludge, or a plant biomass in constructed wetlands.

Now-a-days, the main commercial processes for removing phosphorus from wastewater effluents are chemical precipitation and to a lesser extent, biological removal. The chemical precipitation of phosphorus from wastewater is brought about by the addition of the salts of multivalent metals ions that form precipitates of sparingly soluble phosphates. These precipitated are subsequently settled out by sedimentation. The most commonly used multivalent metal ions are calcium $[\mathrm{Ca}(\mathrm{II})]$, aluminum $[\mathrm{Al}(\mathrm{III})]$ and iron [Fe(III)].

\section{Finding a Sustainable Solution to Struvite PROBLEM}

The most common method of treatment/preventing the formation of struvite, or other forms of phosphate precipitates, in wastewater is to change the characteristics of the wastewater, such as removing phosphate ions and reducing the $\mathrm{pH}$. However, in the current age of sustainable process development, treatment does not necessarily end with removal - rather it is important to provide recovery of material as well. Both phosphorus (present as phosphate in wastewater) and nitrogen (present as ammonium in wastewater) are important nutrients that sustain life on earth. However, like oil, phosphorus is a limited resource, and with dwindling phosphate reserves, it is ever imperative that methods to recover phosphorus from other processes be investigated.

Sidestream treatment of digester supernatant and centrate to recover phosphorus as struvite or other phosphate compounds appears to be the most efficient method of treatment to control phosphate precipitation /struvite/vivianite at wastewater treatment plants. This is because the end product can be used without the need for extensive treatment and processing, as needed with conventional chemical phosphorus removal techniques. Side-stream treatment for phosphorus and ammonia removal usually involves the treatment of digester supernatant, belt-filter press filtrate or centrate [2]. The processes usually occurs in a system called a fluidized bed reactor, which is essentially a circular/cylindrical tank that promotes upwards flow of liquid by injecting the feed (ingredients) from the bottom of the reactor (Fig. 4). Sometimes air bubbles are introduced from the bottom of the reactor to fluidize the struvite pellets. The primary difference between the conventional precipitation and the crystallization process is that in the crystallization process the transformation is controlled accurately. This results in the formation of pellets with a typical size ranging from $1 \mathrm{~mm}$ to $5 \mathrm{~mm}$. The desired size range depends on the use of the struvite; small pellets for quick solubilisation and larger pellets for slow release of the nutrients (nitrogen, phosphorus and magnesium). Without controlling the precipitation process, fine dispersed, microscopic sludge particles are usually formed that reduce the efficiency of nutrient recovery.

Conditions suitable for phosphate-based precipitates such as struvite (MAP) and hydroxyl apatite (HAP) are governed primarily by the supersaturation ratio, which is the degree of supersaturation of the solute (i.e. MAP or HAP) in the solvent. The supersaturation ratio is, in turn, governed by the $\mathrm{pH}$, temperature and presence of competing/impurity ions. To initiate precipitation in the reactor, an increase in $\mathrm{pH}$, though the addition of a base such as sodium hydroxide, is most often used. 


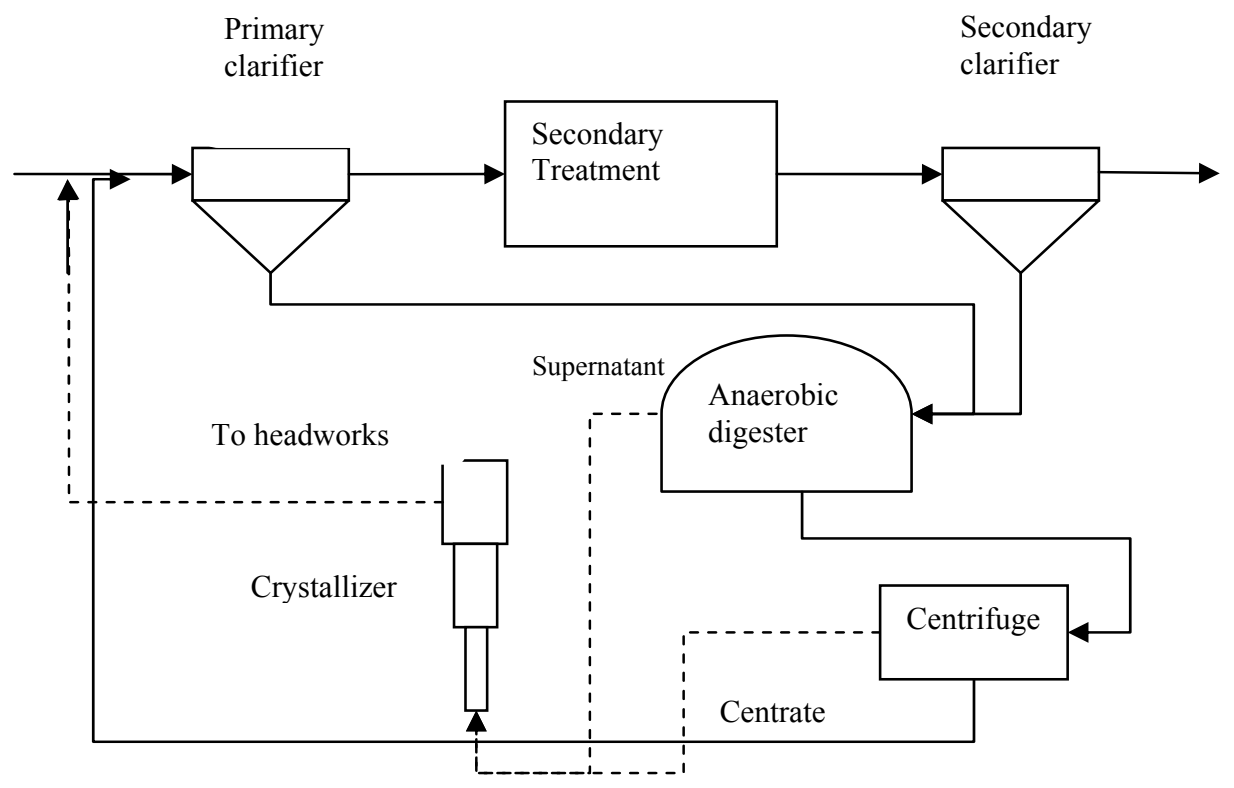

Fig. 4. Possible phosphorus recovery locations

\section{STRUVITE AS A FERTILIZER}

Although struvite might be considered as a main problem occurring in wastewater treatment plants, it can be used in the production of fertilizers and soil conditioners. There is a significant demand for phosphorus as a fertilizer for agricultural purposes due to its slow release properties. If phosphorus recovery happens in form of struvite, it can be used as a slow-release fertilizer which will not leach like conventional fertilizers. One study on the performance of struvite as a fertilizer in comparison to other commercial fertilizers, found that struvite fertilizers were more effective in the growth of Chinese cabbage due to high levels of phosphorus, potassium, nitrogen, and magnesium [12]. Another benefit of struvite as a fertilizer is consideration of heavy metals which are regulated in fertilizers for agricultural purposes. One study showed that struvite formation at certain conditions could be free of a wide range of heavy metals and other heavy metals which precipitated were much lower than the regulatory limits [2].

\section{REFERENCES}

[1] T. M. Suzuki, M. Yano, S. Sumi, M. Honda, Y. Hosoya, and K. I. Yoshida, "Study of the structure of struvite stones with scanning electron microscopy and energy-dispersive X-ray microanalysis," Urologia Internationalis, vol. 58, pp.88-92. 1997.

[2] K. P. Fattah, D. S. Mavinic, F. A. Koch, and C. Jacob, "Determining the feasibility of phosphorus recovery as struvite from filter press centrate in a secondary wastewater treatment plant," Journal of Environmental Science and Health Part A-Toxic/hazardous Substances and Environmental Engineering, vol. 43, no. 7, pp. 756-764. 2008

[3] P. W. Westerman, L. M. Safely, and J. C. Barker, "Crystalline buildup in swine and poultry recycle flush systems," in Proceedings of the 5th International Symposium of Agricultural Wastes, Americal Sociey of Agricultural Engineers, St. Joseph, MO, December 16-17, pp. 613-623. 1985.

[4] X. Mohajit, K. K. Bhattarai, E. P. Taiganides, and B. C. Yap, "Struvite deposits in pipes and aerators," Biol. Wastes. vol. 30, pp. 133-147, 1989.
[5] K. P. Fattah, "Case study - Risk assessment for struvite formation potential at Annacis Island Wastewater Treatment Plant," Report to Metro Vancouver, August 2009.

[6] A. R. Pitman, S. L. Deacon, and W. V. Alexander, "The thickening and treatment of sewage sludges to minimize phosphorus release," Water Research, vol. 25, pp. 1285-1294, 1991.

[7] K. P. Fattah, "Development of control strategies for the operation of a struvite crystallization process," Ph.D. dissertation, Dept. Civil. Eng., University of British Columbia, Vancouver, B.C., 2010.

[8] K. P. Fattah, D. S. Mavinic, and F. A. Koch, "Influence of process parameters on the characteristics of struvite pellets," Journal of Environmental Engineering. December 2010.

[9] A. L. Forrest, K. P. Fattah, DS. Mavinic, and F. Koch, "Standardizing the struvite solubility product for field trial optimization," in Proceeding of International Conference on Nutrient Recovery from Wastewater Streams, Vancouver, B.C., May pp. 10-13, 2009.

[10] C. Sawyer, P. McCarty, and G. Parkin, Chemistry for Environmental Engineering. McGraw-Hill Series in water Resources and Environmental Engineering, New York, U.S.A. 1994.

[11] APHA, AWWA, WPCF, "Standard Methods for the Examination of Water and Wastewater," 19th Edition. American Public Health Association, Washington, D.C. 1995.

[12] C. Lim, M. Kang, S. Lee, and H. Ryu, "H. Evaluation of struvite obtained from semiconductor wastewater as a fertilizer in cultivating Chinese cabbage," Journal of Hazardous Materials, 221, pp.248-255, 2012 .

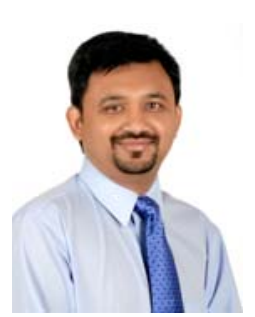

Kazi P. Fattah btained Ph.D. Civil Engineering (Environmental Discipline)from the University of British Columbia. Vancouver, B.C., Canada in 2010. M.A.Sc. Civil Engineering (Environmental Discipline) from the University of British Columbia. Vancouver, B.C., Canada in 2004, B.Sc. Civil Engineering from Bangladesh University of Engineering and Technology, Dhaka, Bangladesh in 2001.

$\mathrm{He}$ is currently an assistant professor at the American University of Sharjah, Sharjah, U.A.E. He has also worked as a consultant at Associated Engineering, Burnaby, B.C., Canada and as an independent consultant to Metro Vancouver. He was a Visiting Assistant Professor at The University of British Columbia. He is actively involved with nutrient removal and recovery from wastewater, sustainable treatment options and water reuse. 